\title{
Decoding the Mystery Behind the Globalization of Chinese Time-honored Brands -- A Case Analysis of Lao Gan Ma Chili Sauce
}

\author{
Wu Yanqin*, Chen Kaiju \\ Center of Business Culture and Philosophy of Culture, Institute of Hermeneutics, Guangdong University of Foreign Studies, Guangzhou, China \\ Email address: \\ 20190310035@gdufs.edu.cn (Wu Yanqin),200010931@oamail.gdufs.edu.cn (Chen Kaiju) \\ *Corresponding author \\ To cite this article: \\ Wu Yanqin, Chen Kaiju. Decoding the Mystery Behind the Globalization of Chinese Time-honored Brands -- A Case Analysis of Lao Gan Ma \\ Chili Sauce. International Journal of Literature and Arts. Special Issue: Humanity and Science: China's Intercultural Communication with the \\ Outside World in the New Era. Vol. 8, No. 2, 2020, pp. 87-92. doi: 10.11648/j.ijla.20200802.18
}

Received: February 27, 2020; Accepted: March 10, 2020; Published: March 31, 2020

\begin{abstract}
Globalization creates a complexly interrelated arena where multiple local differences converge and compete against each other. With respect to its consequent potential impact on various local cultures, Western dominant cultures have been believed as the ultimate destiny for the modernizing cultures under this fast-changing global context, as is more often proved in business where countless companies in developing nations have been keen on learning from Western business giants in the names of modern enterprise administration or international conventions. An originally underprivileged Chinese brand, Lao Gan Ma Chili Sauce, however, has established an invaluably different developmental route by branding with strong Chinese flavors and exposing itself as a miniature of indigenous cultures, successfully growing into a worldwide Chinese cooperation in the past decades. Decoding the mystery underlying its success therefore of significance in cross-cultural business studies. Applying such cultural theories as cultural identity, symbolic consumption and instinct theory, the present study analyzes the business strategies Lao Gan Ma conducts. The qualitative study in this essay demonstrates that cultural resources of a firm are potentially convertible into its powerful capital in the fierce competing world market. More specifically, a unique cultural identity and certain perceived symbolic values retained by a business corporation can serve as alternative and desirable resources to make that firm, especially one in less affluent societies, a competitive contender in the globalized market system. Besides, enterprises whose products cater to the human inner instinct can enjoy exceptional advantages in their penetration into the global market.
\end{abstract}

Keywords: Globalization, Glocalization, Cultural Identity, Symbolic Consumption, Human Instinct

\section{Introduction}

In an increasingly interrelated world system, corporations from affluent countries own some priorities to extend their operations in this huge global market [1]. However, it also imposes serious challenges to the survival of some domestic brands in less developed areas, which once enjoyed great popularity among their local consumers. For instance, some Chinese time-honored brands unable to adapt themselves to this new environment gradually lose their original edges under the threats of swarming emerging market participants from oversea markets, such as Bei Jing Fang Bian Mian (a Chinese brand of instant noodles) and Jian Li Bao (a Chinese indigenous beverage brand.
Notwithstanding in the face of stiff competition from mass peer industries in both home and foreign markets, Lao Gan Ma, a traditional style of chili sauce with authentic Chinese flavors from top and toe, has successfully established itself in the world market. As an outpost of Chinese culture, it had already expanded its business in more than 150 foreign areas with annual sales in excess of 0.6 billion bottles by 2018 (China International Big Data Industry Expo, May 28, 2018). To a certain extent, the worldwide distribution of this Chinese indigenous brand can serve as an exemplar of other Chinese brands and even its counterparts in other peripheral countries in their attempts to avoid being marginalized in the global competitive arena. However, it is worth noticing that an analysis of its success should not be merely oriented to the 
economic or political explanation. Because neither improved local product quality nor government intervention can fully suffice to make any company a powerful global contender [2]. Instead, several particular tactics based on a cultural consideration are also instrumental to a deeper understanding of the smooth development of such kind of brands in the global market. Therefore, the present paper attempts to decode the mystery underlying the globalization of Lao Gan Ma with a focus on cultural explanation where cultural identity, symbolic consumption and instinct theory are involved.

\section{Literature Review}

\subsection{Culture in Globalization Theory}

It is easy to identify that the occurrence of an increasingly globalized world bears much direct relation to economic incentives. Because of the profit-chasing nature of capital, The Great Geographical Discovery in the end of 15 th century automatically began to integrate primarily separate areas on the earth into a big melting spot, which later is labeled as globalization [3, 4]. However, research premised on a traditional economic or political theory is not enough for a comprehensive understanding on this complex phenomenon. Because globalization of "complex connectivity" [3] does not easily lend itself to any encompassing explanation, which instead requires a deliberate consideration of multiple dimensions, especially of cultural perspective [5]. Echoing a cultural bias in globalization theory suggested by Waters, Tomlinson also claims that "the huge transformative processes of our time that globalization describes cannot be properly understood until they are grasped through the conceptual vocabulary of culture" [3]. To recapitulate, despite of its relatively inconspicuous relation with the evolvement of globalization, cultural analysis performing as a prerequisite for a more appropriate interpretation of this globalized world has gradually been acknowledged by relevant theorists.

Furthermore, obvious as the homogeneous trend of local cultures is in this ever-increasingly correlated world, extant literature documents that the intensification of globalization actually promotes a state of hybridity among these local peculiarities instead [3,4]. Cultural globalization of being "deterritorialized" makes possible transnational interaction of physically isolated local cultural entities, which meanwhile discloses its potential to smooth away all their local diversities [3]. However, globalization of its great importance actually lies in the emergence of "subaltern proliferation of difference" [6] in various cultures during their communication with otherness. Robertson also shares the belief that globalization in essence is formulated neither as homogenization nor as westernization, which, on the contrary, should be perceived as an extremely dynamic sphere that consists of twofold process of the particularization of the universal and the universal of the particular [4].

\subsection{Cultural Identity in Globalization}

Identity in its cultural sense is not merely limited to a convenient synonym for physical fingerprints or DNA of human creatures. Surpassing its biological reference, cultural identity can be generally reduced to the emotional experience and a sense of belonging shared simultaneously by a certain social community, which also distinguishes them from otherness in the globalized world [7].

Cultural identity theory can contribute to a more appropriate understanding of exchanges in this closely correlated world. The internal conflicts of modernity and a very tangible rise of globalized process have the great influence in the eruption of identity crisis of the present throughout the world [8]. Consumers of pleasure-seeking today indulge in exploring new experience in foreign goods available in the globalized market, which eventually has fostered their uncertainty about the intrinsic identity $[9,10]$. Moreover, the issue of identity crisis can also be traced back to the intensified population mobility across national boundary in the process of globalization. Immigrants exposed to a new geographical location often feel their incompatibility with other cultural community, which consequently leads to their anxiety about their original cultural identity.

Cultural identity, therefore, is recognized as a valued point for the investigation of the business exchanges of enterprises in transnational capitalist system. He and Wang note that in response to the constant threats of its foreign rivals (such as Nike and Levis), Meters/bonwe (a Chinese domestic clothing brand) endeavors to re-stimulate customers' purchasing motivation through a strategic emphasis on its intrinsic Chinese elements [10]. Through their analysis, they then conclude that cultural identity is conducive to "enhancing customers' relative preference and actual purchasing of domestic brand" [10]. Due to its inherent disadvantage of a lack of economic capital in the global arena, Ger also suggests that hamams (Turkish baths) promote itself with the unique cultural resources embedded in its designs to defend against the threat of marginalization [1].

\subsection{Symbolic Consumption in Global Theory}

At first sight, it can be conjectured that customers' incentive for purchase depends heavily on the extent that the physical properties or utilitarian attributes of these goods or services can satisfy their needs [16]. Paradigmatic consumers' incentives can be illustrated as their needs to maintain bodily function. However, customers' primary concern for products has gradually shifted to the purported symbolic meanings embedded in those items in the globalized world, which now have elevated as a salient determinant of their purchase behaviors $[1,2]$.

Similarly, the successful operation of any brand in the worldwide market cannot be simply construed to its advanced physical quality [2]. Moreover, the underlying symbolic value, which arises from a thoughtful management of a series of codes, plays as an important contributor to its outstanding business performance worldwide $[2,11]$. By analyzing the Chinese customers' response to a Canadian pork sausage, Zhou and Hui [2] in their empirical research conclude that symbolic value is of great significance for the prevalence of 
both conspicuous and inconspicuous brands of foreign origin. Besides, Watson [11] claims that the wide distribution of McDonald in foreign streets can be traced back to its brilliant employment of symbolic value where it positions itself as a gateway to status enhancement in developing nations. This sort of symbolic attributes are likely to activate a blind veneration for other foreign food sand breed an unconscious inability to appreciate their local commodities if a perceived unequal distribution of power exists between two areas.

\section{Mysteries Behind the Globalization of Lao Gan Ma}

\subsection{Dynamic Interaction Between the Local and the Other}

\subsubsection{A Deference to the Local and an Appropriation from the Other}

Western ${ }^{1}$ culture embedded in commodity exchanges is seemingly going to devour all of the wretched otherness in less affluent countries in the globalized competitive arena $[12,13]$. Notwithstanding westernization cannot be recognized as a corollary to the globalization phenomenon, its overwhelming influence on other local cultures also remains noticeable. A representative instance can be illustrated by the worldwide prevalence of some phenomena, for example, Coca-colonization [1] and McDonaldization [14]. The Chinese being over enthusiastic about Western cultures is rather obvious in the exponential growth of McDonald in their domestic supermarkets. As a food chain brand from America, McDonald is labeled as efficient, predictable and calculable which responds to the prototypical lifestyle of Americans. Chinese customers' rushing to McDonald can be partly ascribed to their inner desires for the symbolic recognition of certain admire identities, which are likely to be acquired through their consumption of this American-style food.

Local culture has been propelled to prominence today in China while it is suffering serious cultural shock from swarming foreign cultures. An underlying relation between food and culture proposed by Tomlinson verifies that food in an area carries the history of the formation of its unique symbolic value and perceived cultural identity [3]. McDonald has simultaneously brought the Chinese their Western sauces (such as tomato ketchup and sesame sauce), which actually are embedded with a unique identity of American culture. Similarly, Lao Gan Ma, a time-honored Chinese brand, plays as an authentic representative of the cooking culture in southwest China. Contrary to the limited materials in western sauces, this Chinese sauce generally emphasizes an appropriate mixture of various kinds of food substances, which generally consists of chicken, fermented soybean, chill oil and various spices (anise, Sichuan pepper, garlic, etc.). The unique cooking method and spice culture together contribute to the local peculiarities retained by Lao Gan Ma, which

1 "Western" in the present research refers to the developed countries at economic advantage in the world where a capitalized "W" is to differentiate them from the western areas of geographical reference. distinguish it from its foreign rivals. Western-style sauces have actually gained popularity among the Chinese in the social context of globalization, undoubtedly influencing the business performance of Chinese traditional sauce industry. Faced with the threat of marginalization, traditional wisdom at its logical extreme ever mistakenly suggested that firms from less affluent countries should transfer business practices from the west to achieve their positive twists [1]. Instead, on the basis of its unique cooking method and cooking culture, Lao Gan Ma develops these local peculiarities into its innovative reconstruction where their product variety is increasingly enriched to cater to customers' different preferences. Its reconstructive attempts in deference to its unique culture identity have eventually helped them regain much popularity among consumers.

However, it is worth noticing that safeguarding local culture cannot be simply equated to an obstinate insistence on its own cultural identity. Keeping local culture in complete sameness is impossible to be achieved in an era of diversity. On the contrary, various local entities, premised on the completeness of its essential cultural identity, are supposed to reconstruct themselves in the global encounter. Modern technology makes possible the project of advertisements from the most remote end of the globe, which fosters its penetration process of Western sauces into Chinese market [10]. Threatened by an accelerating loss of customers, Lao Gan Ma that never advocated itself shifts to the epoch-making employment of this privileged cultural pattern to promote its chili sauces. This new attempt, which signals an appropriation from the other, has the potential to reactivate the common experience Lao Gan Ma shares together with its customers who then may return to their original preferences towards this Chinese-style sauce.

\subsubsection{A Favored Adaptation to the Other}

Most importantly, a unique foreign identity is not fully responsible for the unfading prevalence of $\mathrm{KFC}$ and McDonald in foreign markets. A feasible approach to improving customer loyalty, instead, can be described as "clothing foreign brands in local costumes" [2]. Localization is recognized as an emerging stage of globalization where foreign brands add some local colors in their expansion overseas. Besides, the ultimate outcome of globalization will not be featured neither as a type of unidirectional transmission of Western culture $[3,6]$. Reconstructive local culture in less affluent areas introduced by its efforts to bear upon Western cultural exports enables it to yield its own fruits, with which it can compete against Western cultures. What counts as significant for the diversity of globalization are the participants of various local cultures in less affluent areas, which therefore require their continuous efforts to export their own local peculiarities.

In the recognition of the success of this Chinese time-honored brand has obtained worldwide, Ma Ningyu points that Lao Gan Ma has established itself in more than 150 countries (China International Big Data Industry Expo, May $28,2018)$. The widespread prevalence of Lao Gan Ma on the shelves of this huge world supermarket is significant in its 
special identity as an indigenous culture from less affluent countries. To recapitulate, it has verified that the prosperity of non-Western cultures need not come at the expanse of erasing their local cultural identities completely but through moderate reconciliation with the globalized world. For the purpose of extending its business scope outside China, Lao Gan Ma chooses to adjust its authentic Chinese flavor to foreigners' preference who generally cannot tolerate too spicy taste. Westerners reportedly indulge in Lao Gan Ma in that it achieves a perfect complexion of multiple flavors what they can hardly experience in their own sauces. The external manifestation of Chinese food culture in Lao Gan Ma might more or less appear certain degree of adjustments directed at obtaining identity recognition from otherness in the global market. Whereas its core cultural identity, which exposes itself as the unique cooking method and spice culture, is what Lao Gan Ma stands fast even in the global arena. It can be conjectured that its successful practice of globalization can be dated back to the reciprocal interplay of its unique perceived culture identity and continuous adjustments to the need of foreign cultural tradition.

\subsection{Exceptional Advantages of Appetite Catching and Desire Catching}

Humans being divine and material simultaneously in inner heart together shape various complete social subjects. Humans of materialism refer to their pursuits of primitive desires, for example, a desire for sensual pleasure. On the contrary, human divinity (such as inner spirit and social value), is correlated with their higher level of qualities in essence. Our ancestors show worships towards the mysterious nature which enjoys ultimate power to decide whether their stomachs can be satisfied with enough food. Due to their limited power, our ancestors behaved rather powerless towards the control of nature. Consequently, in order to survive, they could not do much but strictly obey the evolution course of nature, which left little room for venting their inner desires. The subsequent rigid stratified system in traditional society also imposed various sets of rules on their behaviors that they needed to follow otherwise they would be punished by the authority. Not until the occurrence of modern society did their desires receive a few concerns when production capacity was greatly improved and power distance gradually faded away. Modern society is thus prominent in its strong stimulation towards the inner desire of humans [16], who fortunately find outlets of their suppressed desires by virtue of this developed society.

Chen and Zhang reveal that living instinct and death instinct dwell together in human inner heart [9]. Living instinct refers to the positive perspective of human spirits, for instance, an instinct for love and longevity. Death instinct in one's consciousness at its large part is considered as evil (such as damage and destruction), which, however, is the final destiny of every human creature. Humans in their pursuits of living instinct are inevitably accompanied by the influence of death instinct. This sort of contradictory relation between the two types of instincts leads to the emergence of hedonism, which urges them to enjoy available pleasures in their limited lives.
At the mercy of hedonism, an intrinsic eager for sensual pleasure is nourished in human nature no matter of their consciousness.

Both their materialism and instinct assert the existence of pleasure-seeking nature in human sub-consciousness. Meanwhile, their primitive thirst for sensual pleasure, one of which today can be identified as their growing curiosities about difference, may find its culmination in modern society where security from abundant material resources and liberation from rigid rules assists as a powerful umbrella of their desires [1]. As its Western counterparts, Lao Gan Ma also can expand its operations overseas by virtue of the globalized trend. Different from most Western food that sets specific rules on the proportion of materials, Chinese food tends to place more emphasis on the instinct and experience of cooks, which also constitutes to strong mysterious colors and inimitability of its unique cultural identity. Besides, the difference between Chinese and Western food culture can be attributed to their conceptions on diet. Westerners' consuming food in scientific collocation largely stem from a pure intention of maintaining normal function of their physical bodies. On the contrary, Chinese food culture often carries strong emotional colors whose ultimate goal points to psychological satisfaction. Its substantial difference from Western sauces, therefore, has successfully activated westerners' interest in this exotic flavor that can be consumed by most of them. Furthermore, spice culture which constitutes to the unique cultural identity supposedly enjoys exceptional advantages at the satisfaction of humans' sensual pleasure [15]. In short, a unique cultural identity implied in Lao Gan Ma chili sauce, which cater to both customers' inner desire and appetite preference, facilitate the business expansion of Lao Gan Ma in oversea markets.

In the final analysis, the pursuit of sensual pleasure is rightly the reflection of human nature, where Lao Gan Ma as a food industry can enjoy inherent advantages in its going-out process. Consequently, compared with other industries, less effort is needed for this food brand to be recognized by foreigners in the global market. Therefore, the small jar of Lao Gan Ma exposes the authentic flavor of Chinese food culture from inside to outside, successfully making itself stand out among other sauces and stimulating great curiosities of foreigners overseas. Motivated by their instinctive desires, not surprisingly, foreign consumers are fairly pleased to consume this kind of Chinese mysterious flavor available in the era of globalization. Therefore, by virtue of the local peculiarities implied in its unique cultural identity, it is not odd that Lao Gan Ma has obtained optimistic sales performance in the global arena.

\subsection{Symbol Consumption}

\subsubsection{In the Name of Love}

As a foremost theorist, Baudrillard depicts postmodernism as the death of human subjects or the end of individualism [16]. People enjoying toxic pleasure brought up through the swarming difference in the globalized world are quickly replaced by their endless anxiousness and loss about life. As a 
result, they hasten to search for some comforts from the external world through commodity consumption. With an aim to activate transference effect [17] among consumers, Lao Gan Ma shrewdly conceals its inherent nature of chasing economic profits and shifts to show its concerns towards the whole society.

The successful representation of its love and care of Lao Gan Ma towards the society has been achieved through its image design, brand name as well as advertisement innovation. Images with young people in pretty physical appearance are supposed as greatly efficient in attracting attentions from people. Contrary to that logic, Lao Gan Ma deliberately places an extraordinary average-looking and old Chinese female on its product package, which conversely arouses strong curiosities of foreign consumers. Besides, its brand image also suggests a deliberate arrangement on the external characters of this old woman, (such as her serious face and normal hairstyle of central parting), which can be explained by the utilization of paralanguage. Advertisers using paralanguage, which includes sounds, body language and other items simultaneously occurring with the subjects, can aid and even replace language to promote a smooth communication with audience and consequently make their products more attractive [18]. General appearance, black cloth and white apron together formulate a prototypical miniature of the Chinese traditional housewife, a group of people who are generally acknowledged as kind and considerate. This sort of unique consideration behind its average jar has successfully conveyed to its consumers that this sauce is preoccupied with soft tenderness.

The second strategy that Lao Gan Ma successfully employs to comfort consumers is its special brand name, which refers to a type of people who do not have kinship relation with their children but still willingly show their selfless love to them in China. Its brand name has even been translated into godmother who enjoys superior status in the inner heart of foreign people. All these brand names appropriate the characteristics of maternal love, which is an acknowledged pronoun for the most selfless love in the world. As a result, it has converted its profit-oriented nature into disguised humanistic concerns for the current plights modern people encounter. Furthermore, different choices of salutation in China can suggest the distance with different social subjects. Though adding $L A O$ in front of the original salutation can show respect to the senior. Moreover, it also acts as a favorable and efficient approach to shortening the emotional distance among people. The ingenious tactics of Lao Gan Ma adopts lead to its successful establishment of a much closer intimacy with potential customers. It of course can be conceived as a seemingly reasonable law that consumers rush to buy this kind of piratical maternal love who are desperate for some comforts in their gloomy and depressive life.

Furthermore, modern advertisements in their designs have already abandoned the original pattern that directly introduces the products' outstanding performance to the audience [16]. Discourse conversion has gradually evolved into a favored tactic by advertiser capitalist, who now shift to move the audience through their efforts to build emotional contacts with them. It is generally realized through purposeful appropriation of various symbolic emotional resources into their advertisement clips, which at first sight bear no relevance with utilitarianism or commercialism. Lao Gan Ma depicts the real living state of modern people by straightforwardly pointing to common problems they confront, effectively conveying positive messages of its understanding of their plights and subverting the traditional concept of advertisements through advocating itself as human-oriented. These skillful strategies Lao Gan Ma carries out have warranted its products a sense of illusion that presents human sympathy and even mother-like love towards consumers rather than selling merely for their own economic interests. Consequently, all these manipulative concerns Lao Gan Ma shows facilitate its efforts of being accepted by consumers and push forward their market penetration in the globalized market.

\subsubsection{Wonderful but Empty Promises}

According to Baudrillard, symbolic benefits are a salient determinant of customers' consumption behaviors. The physical properties of products, of course, cannot be strong enough to activate customers' purchasing motivation, which instead must be grafted with a set of irrelevant meanings. The original relationship between the signifier and the signified of symbols [19] has already been canceled by great arbitrariness in modern society. The arbitrary signifier chain about Lao Gan $\mathrm{Ma}$ is another tactic it adopts, where beautiful but unrealistic dreams abound.

Consuming food from home country motivated by status seeking today prevails among a special group of social subjects who live overseas and lose physical connections with their home countries in the globalized world. Any formation of a certain group cannot be simply attributed to their simultaneous share of a common physical area. More importantly, it is the common cultural experience that shapes their unique cultural identity [7, 10]. Great mobility led by "physical proximity" [3] from another perspective has caused anxieties of overseas Chinese towards their intrinsic identities. The local peculiarities embedded in Chinese food culture do rightly shape its distinctive cultural identity from otherness. Overseas Chinese feel strong incompatibility with foreign culture when they are suddenly exposed to a new environment, which leads to their obsession with their local flavors. Chinese time-honored brands with common experience of generations of the Chinese people constitute to a sort of special cultural emotions implied in this brand. Consequently, it is likely to arouse special memories of the overseas Chinese about their dear homeland and generate a sense of illusion that they can go back to their roots through consuming this Chinese chili sauce. Directed at its symbolic meaning of homeland, the overseas Chinese in absolute willingness rush to consume Lao Gan Ma to alleviate their anxieties and nostalgia, as well as to reconfirm a sense of belonging and their intrinsic cultural identity.

The signifier that diverts from general conventions can build empty connections with any other irrelevant reference and consequently realize its own carnival in advertisements. 
Advertisers using "floating signifier" [17] in their advertisements successfully associate their products with some admired and noble features artificially, which together lead to the rampant force of those terrific but empty promises in the whole society. By conducting a contrast with different stages of protagonists' life in its advertisements, Lao Gan Ma Chili Sauce has formed a deliberate artificial signifier chain in its products, which can be represented through a math formulas: "Lao Gan Ma=success=harvest of love."

Supreme power of smoothing away all problems and conflicts is another distinguished feature guaranteed by floating signifier in advertisements. Life in complexness poses many challenges to modern people, which they often feel their limited capacity of handling with, consequently causing their extraordinary depression in life. Both conflicts presented in its advertisements between protagonists and their jobs, as well as their emotional life should simultaneously have been solved in a perfect but unreasonable manner, efficiently leaving consumers an impression that Lao Gan Ma enjoys magic power of giving them a hand in achieving success and finding their own soul mates in their gloomy life. Artificial signifier chains indulge in making such sort of terrific promises towards solving all puzzles and difficulties, consequently strongly luring customers into buying their products. However, an interesting phenomenon occurs that advertisers need not shoulder any responsibility for the fulfillment of these empty promises, as if they enjoy endless line of credit from consumers.

\section{Conclusion}

The present research, from the perspective of cultural identity, symbolic consumption and instinct theory, decodes the motivations to success of a Chinese brand Lao Gan Ma Chili Sauce in the social context of globalization. It therefore suggests that, to survive in the competitive global arena, cooperation in less affluent countries can alleviate the sufferings from its inadequate economic capitals through reconstruction of their local culture resources. In response to the constant threats of Western sauces, Lao Gan Ma endeavors to annex the global into its own cultural practice and even to out-localize its local identity as an outpost of Chinese culture. Besides, the unique symbolic value embedded in this Chinese-style sauce, together with its potential to satisfy human instinct, also pushes forward its market penetration into foreign markets. Globalization is identified as an irresistible trend of the present world where any plea for a return to the previously isolated state is thought as impossible and irrational. What really counts is how various local cultures, especially those in less affluent areas, can achieve their own optimistic negotiation with this era by virtue of their local peculiarities. Other Chinese indigenous brands, even their counterparts in other less affluent countries, should learn from these brilliant tactics employed by Lao Gan Ma in order to survive in the wave of globalization.

\section{References}

[1] Ger, G. (1999). Localizing in the global village: local firms competing in global markets. California Management Review, 41 (4): 64-83.

[2] Zhou, L., \& Hui, M. K. (2003). Symbolic value of foreign products in the people's republic of china. Journal of International Marketing, 11 (2): 36-58.

[3] Tomlinson, J. Globalization and Culture, 2rd ed., vol. 1. Chicago: University of Chicago Press, 1999, pp. 2-8.

[4] Robertson, R. Globalization: Social Theory and Global Culture, 2rd ed., vol. 6. London: Sage, 1992, pp. 177-178.

[5] Waters, M. Globalisation. 2rd ed., vol. 1. New York: Routledge, 2001, pp. 9-10.

[6] Bhabha, H. K. 2rd ed., vol. 9. The Location of Culture. New York: Routledge, 2004, pp. 204-216.

[7] Aristova, N. (2016). Rethinking cultural identities in the context of globalization: linguistic landscape of Kazan, Russia, as an emerging global city. Procedia-Social and Behavioral Sciences, 236: 153-160.

[8] Han, Z. (2005). On the multi-cultural identity in the process of modernization. Seeking Truth, 32 (5): 21-26.

[9] Chen, K. J. \& Zhang, J. (2016). A critique on pan-amusement of postmodern culture. Philosophical Research, 7: 120-126.

[10] He, J., \& Wang, C. L. (2015). Cultural identity and consumer ethnocentrism impacts on preference and purchase of domestic versus import brands: an empirical study in China. Journal of Business Research, 68: 1225-1233.

[11] Watson, J. L. (2000). China's big mac attack. Foreign Affairs, 79 (3): $120-134$.

[12] Jin, Y. P. (2013). Glocalization, local globalization and interculturality. International Cultural Administration, 2: $12-16$.

[13] Radhakrishnan, R. (2001). Globalization, desire, and the politics of representation. University of Oregon, 53: 315-332.

[14] Ritzer, G. (2004). The "Mcdonaldization" of society. The Journal of American Culture, 6 (1): 100-107.

[15] Schneider, J. (1977). Was there a pre-capitalist world system? Peasant Studies, 6: 2-29.

[16] Baudrillard, J. (1993). Symbolic Exchange and Death. London: Sage.

[17] Ray, L. (1999). Why we give: testing economic and social psychological accounts of altruism. Polity, 30 (3): 383.

[18] Chen, K. J. 1rd ed., vol. 4. A Critique on Pan-Amusement of Postmodern Culture. Beijing: Intellectual Property Publishing House, 2018.

[19] Saussure, D. F. "Cours de linguistique générale," The Commercial Press. Beijing, vol. 4, pp. 100-102, November 1980. 